\title{
Experimental justification of the stability of the floating unit
}

\author{
Vladimir Zimnyukov" , Marina Zborovskaya, Vasiliy Fartukov, and Anton Zaitsev \\ Russian State Agrarian University - Moscow Timiryazev Agricultural Academy, Moscow, Russia
}

\begin{abstract}
One of the main tasks arising when installing a floating hydroelectric power unit on a foundation without preliminary excavation is a thorough justification of the shear stability and bearing capacity of the "floating hydroelectric power unit foundation" system on a complex geological massif. Failure to take into account these factors can lead to serious consequences during the landing of the structure in the target and further operation. It should be emphasized that this problem still includes a number of difficulties and does not always allow obtaining exact solutions in a volumetric setting. Based on the selection of a wide range of model materials, bases of various capacities were modelled for four models. In this case, the shear real characteristics of alluvial soils and their change after reinforcing cementation were taken into account. The studies were carried out on 4 models under static loads with bringing them to destruction. The models reproduced the real geological conditions at the base of the block, simulated deformation, and shear characteristics. Indicator diagrams of displacements, damage patterns, and generalized safety factors for bearing capacity were obtained. Model tests have shown that reinforcing cementation reduces not only the values of horizontal and vertical displacements of structures but also leads to a significant increase in the safety factor.
\end{abstract}

\section{Introduction}

The main problem that arises when installing a floating hydroelectric power plant (HPP) unit directly on the base is the need for careful consideration of the physical and mechanical characteristics of the soil that composes it [1-4].

Underestimation of the engineering and geological conditions of the installation area often causes the emergency state of the structure during the construction period and during the operational period.

All this makes it necessary, along with computer calculations according to special programs, to conduct model studies to substantiate the reliability of the floating block

\footnotetext{
*Corresponding author: zimnyukov@rgau-msha.ru
} 
operation on a complex soil mass. In recent years, due to the difficulties in organizing research on physical models, this issue has been practically ignored, which often leads to undesirable consequences.

As the initial data for assigning the design characteristics of the foundation, the engineering and geological conditions in the sections of the Angara - Yenisei cascade were considered. Options for installing a floating block on a base made of alluvium, which is most common in this area, were studied.

Previous studies [5-11] have shown that base deformations caused by the displacement of the structure model under the influence of applied loads when bringing the model to failure can spread to a considerable depth. In this case, the physical and mechanical characteristics of rocks lying below those located directly under the structure can affect the nature of destruction and the magnitude of the breaking load. In this regard, it seems necessary to model the underlying alluvium rock as well. In the sections under consideration, the underlying layer is represented by a rock of intense weathering (zone "A"), the characteristics of which are given in Table 1.

Separations of the destroyed rock within zone "A" in the upper part are much less than in the lower one. In this regard, for more accurate reproduction of the geomechanical properties of the base, it was decided to model the underlying rock in two tiers: the upper of them is transitional from alluvium to destroyed rock with larger parts. Considering that the deformative characteristics of the base, along with the shear strength characteristics, can be of decisive importance when modelling the base. This significantly complicated the task of selecting model materials since it required linking different layers of the model base taking into account three factors: $\mathrm{c}, \varphi$, and $\mathrm{E}$ (respectively, adhesion, angle of internal friction, and deformation modulus).

\section{Materials and Methods}

\subsection{Initial data for modeling loads}

Shear tests of the floating block models were carried out under static loads. The own weight of the unit, equipment, weighing, and anti-filtration back pressure was taken into account; hydrostatic loading in the upstream and downstream.

Loads were calculated based on the following assumptions:

it is considered as the worst case of repair of the draft pipe from the point of view of ensuring the stability of the block in shear;

adopted head $\mathrm{H}=15 \mathrm{~m}$ at a relative elevation DSL 5.5m;

relative lower elevation of the block bottom - $7.25 \mathrm{~m}$;

the relative upper elevation of the block is taken on the basis of a margin above the HWL of $3 \mathrm{~m}$ and is $16.25 \mathrm{~m}$;

block dimensions in plan $28 \times 28 \mathrm{~m}$ (for the layout of a hydroelectric power station building with horizontal turbines and a bell pipe); the height of the block at marks $-7.25 \mathrm{~m}$ and $16.25 \mathrm{~m}$ is $23.5 \mathrm{~m}$ (Figure 1);

the given filtration diagram is shown in Figure 1;

the given hydrostatic pressure diagram is shown in Figure 2;

the volume of concrete is $7322 \mathrm{~m} 3$, the weight of concrete at $\gamma_{-} \mathrm{c}=2,5 \mathrm{t} / \mathrm{m} 3$ is $18305 \mathrm{t}$; weight of water above the block elements for the case of repair of the exhaust pipe is $4298 \mathrm{t}$;

equipment weight is $157 \mathrm{t}$;

Prismatic strength of concrete is $\mathrm{R} \_$pr $=20,0 \mathrm{MPa}$ (for 180 days). 


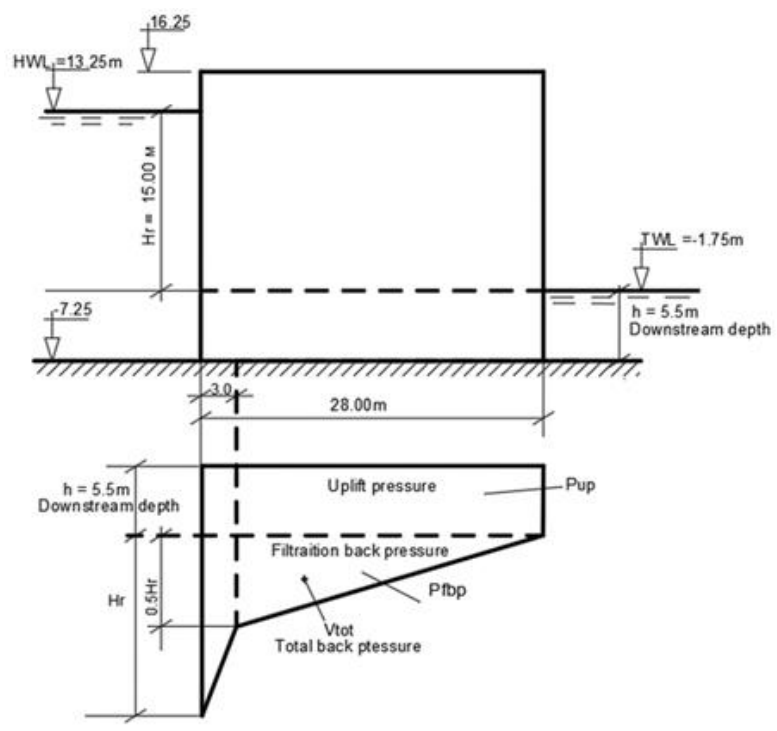

Fig. 1. To calculate the load on the unit from the filtration back pressure

Table 1. Characteristics of rocks considered as the bases of floating blocks in the sections of the Angara-Yenisei cascade

\begin{tabular}{|c|c|c|c|c|c|}
\hline \multirow[b]{2}{*}{ Side } & \multicolumn{5}{|c|}{ Alluvium characteristics } \\
\hline & Name of soils & $\begin{array}{c}\text { Power, } \\
\text { m }\end{array}$ & $\begin{array}{l}\text { Ground } \\
\text { grip } \\
\mathrm{C}, \mathrm{MPa}\end{array}$ & $\varphi / \operatorname{tg} \varphi$ & $\begin{array}{l}\text { Soil deformation } \\
\text { modulus } \\
\mathrm{E}, \mathrm{MPa}\end{array}$ \\
\hline Murozhny & - & $0.5 \div 3$ & - & - & - \\
\hline Savinsky & $\begin{array}{l}\text { silty sands, } \\
\text { pebble soils }\end{array}$ & 1.5 & 0 & ${\frac{22^{0} \div 31^{0}}{0.4 \div 0.6}}^{0}$ & - \\
\hline Predivinsky & pebble soils & 3.7 & 0 & $\frac{22^{0} \div 31^{0}}{0.4 \div 0.6}$ & - \\
\hline Osinovsky & $\begin{array}{c}\text { sands of } \\
\text { various sizes } \\
\text { and gravel- } \\
\text { pebble soils }\end{array}$ & $4 \div 10$ & 0 & $\frac{39^{\circ}}{0.8}$ & 50 \\
\hline Yartsevsky & $\begin{array}{l}\text { sands of } \\
\text { various sizes } \\
\text { and gravel- } \\
\text { pebble soils }\end{array}$ & $5 \div 18$ & 0 & $\frac{39^{\circ}}{0.8}$ & 50 \\
\hline Kolmogorovsky & $\begin{array}{c}\text { sands of } \\
\text { various sizes } \\
\text { with gravel, } \\
\text { pebbles, and } \\
\text { boulders }\end{array}$ & $5 \div 15$ & 0 & $\frac{40^{\circ}}{0.85}$ & 70 \\
\hline
\end{tabular}




\section{Continued table 1}

\begin{tabular}{|c|c|c|c|c|c|c|}
\hline \multirow[b]{2}{*}{ Side } & \multicolumn{6}{|c|}{ Characteristics of the eroded rock zone "A" } \\
\hline & Name of soils & $\begin{array}{c}\text { Power, } \\
\text { m }\end{array}$ & $\begin{array}{l}\text { Ground } \\
\text { grip } \\
\mathrm{C}, \mathrm{MPa}\end{array}$ & ${ }^{\varphi} / \operatorname{tg} \varphi$ & $\begin{array}{c}\text { Soil } \\
\text { deformation } \\
\text { modulus } \\
\text { E, MPa }\end{array}$ & $\begin{array}{c}\text { Prismatic } \\
\text { strength } \\
\mathrm{R}, \mathrm{MPa}\end{array}$ \\
\hline Murozhny & - & $2 \div 10$ & - & - & - & - \\
\hline Savinsky & $\begin{array}{c}\text { lumps, } \\
\text { crushed stone, } \\
\text { gruss with } \\
\text { sandy loam } \\
\text { aggregate: } \\
\text { graphitized } \\
\text { limestone }\end{array}$ & 5.5 & 0.02 & $\frac{29^{\circ}}{0.55}$ & - & $20 \div 30$ \\
\hline Predivinsky & $\begin{array}{c}\text { lumps, } \\
\text { crushed stone, } \\
\text { gruss with } \\
\text { sandy loam } \\
\text { aggregate: } \\
\text { biotite } \\
\text { gneisses, } \\
\text { hornblende } \\
\end{array}$ & 6.3 & 0.02 & $\frac{31^{0}}{0.6}$ & - & 100 \\
\hline Osinovsky & $\begin{array}{c}\text { shale } \\
\text { carbonate- } \\
\text { actinolite }\end{array}$ & large & 0.2 & $37^{\circ}$ & 9000 & - \\
\hline Yartsevsky & Jurassic clays & - & 0.04 & $\frac{20^{\circ}}{0.37}$ & 30 & - \\
\hline Kolmogorovsky & $\begin{array}{l}\text { conglomerate } \\
\text { s, gravelites, } \\
\text { sandstones on } \\
\text { lime cement } \\
\\
\text { sands of } \\
\text { different } \\
\text { sizes, } \\
\text { kaolinized } \\
\text { quartz }\end{array}$ & 10 & 0.1 & $\begin{array}{l}\frac{31^{\circ}}{0,6} \\
\frac{30^{\circ}}{0.58}\end{array}$ & 1500 & - \\
\hline
\end{tabular}

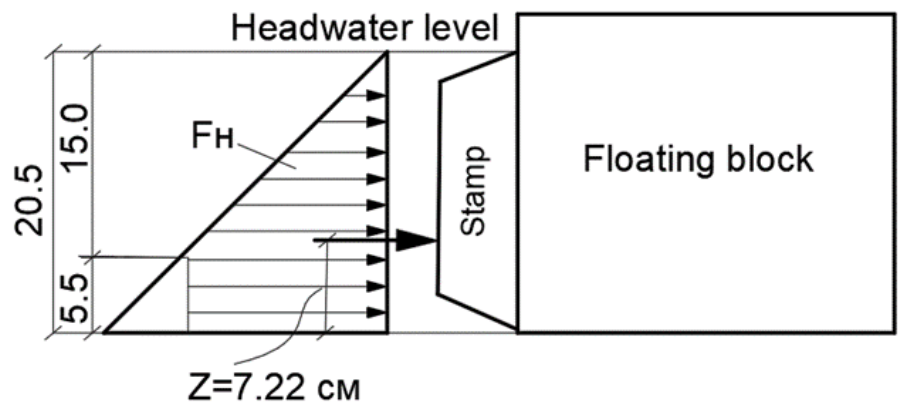

Fig. 2. Diagram of hydrostatic pressure 


\subsection{Description of the models accepted for research}

All models of floating blocks are made on a scale of 1: 100 in the form of rigid stamps with dimensions in plan $28 \times 28(\mathrm{~cm})$ and a height of $23.5 \mathrm{~cm}$ (Figure 1). The bases of the models are made as follows:

Model No. 1 - real shear characteristics of alluvial soils are simulated to a depth of $5 \mathrm{~m}$

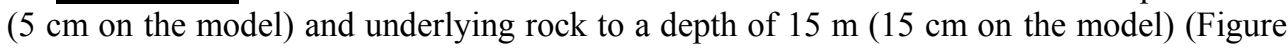
3a);

The following characteristics are taken as the initial data for modeling alluvium: $\mathrm{c}=0$, $\varphi=39^{\circ}, \operatorname{tg} \varphi=0.8, \mathrm{E}=70 \mathrm{MPa}$.

The base model in the zone of intense weathering (the underlying rock of zone "A" with a total thickness of $15 \mathrm{~m}(15 \mathrm{~cm}$ on the model) is made in two tiers. The upper tier (zone "A1") with a thickness of $3.6 \mathrm{~m}(3.6 \mathrm{~cm}$ on the model) is models from 1 to $3 \mathrm{~cm}$ with characteristics: $\mathrm{c}=0, \varphi=38^{\circ}, \operatorname{tg} \varphi=0.785, \mathrm{E}=20 \div 30 \mathrm{MPa}$.

The lower tier (zone "A2") with a thickness of $11.4 \mathrm{~m}(11.4 \mathrm{~cm}$ on the model) is made of blocks stacked in three layers with a thickness of $3.8 \mathrm{~m}$ (from $3.8 \mathrm{~cm}$ on the model) each.

Initial characteristics of the underlying rock in the "A2" zone: $\mathrm{c}=0.02 \div 0.2 \mathrm{MPa}, \varphi=$ $31^{\circ} \div 37^{\circ} ; \operatorname{tg} \varphi=0.6 \div 0.75, \mathrm{E}=1500 \mathrm{MPa}$.

Model No 2 - real shear characteristics of alluvial soils are simulated already at a depth of $15 \mathrm{~m}(15 \mathrm{~cm}$ on the model) and the underlying rock to a depth of $15 \mathrm{~m}(15 \mathrm{~cm}$ on the model) (Figure 3b);

The following characteristics were taken as the initial data: $\mathrm{c}=0, \varphi=39^{\circ}, \operatorname{tg}=0.8, \mathrm{E}=$ $70 \mathrm{MPa}$.

For the underlying rock:

in the "A1" zone: $\mathrm{c}=0, \varphi=38^{\circ}, \operatorname{tg} \varphi=0.785, \mathrm{E}=20 \div 30 \mathrm{MPa}$;

in zone "A2": $\mathrm{c}=0.02 \div 0.2 \mathrm{MPa}, \varphi=31^{\circ} \div 37^{\circ} ; \operatorname{tg} \varphi=0.6 \div 0.75, \mathrm{E}=1500 \mathrm{MPa}$.

Model No. 3 - the model No. 1 foundation is simulated by cementation. Under the bottom of the floating block, the shear characteristics of alluvial soils are modeled on the state after reinforcing cementation over the area of the block bottom, the full power of alluvium, and the upper tier of destroyed rock with a depth of $8.6 \mathrm{~m}(8.6 \mathrm{~cm}$ on the model $)$ (Figure 3c). As you know, strengthening cementation increases the shear characteristics of alluvial soils by $20 \%$. Thus, the initial characteristics are taken as follows:

for the reinforced part of the base by the area of the block sole to a depth of $8.6 \mathrm{~m}$ :

$\mathrm{c}=0.2 ; \varphi=36^{\circ}, \operatorname{tg} \varphi=0.73$.

There are no field data on the strength and deformation characteristics of alluvium after strengthening cementation.

For the rest of the alluvial base:

$\mathrm{c}=0, \varphi=39^{\circ}, \operatorname{tg} \varphi=0,8, \mathrm{E}=70$ Мпа.

For the bottom three layers of the underlying rock:

$\mathrm{c}=0.02 \div 0.2 \mathrm{MPa}, \varphi=31^{\circ} \div 37^{\circ} ; \operatorname{tg} \varphi=0.6 \div 0.75, \mathrm{E}=1500 \mathrm{MPa}$. 
a)

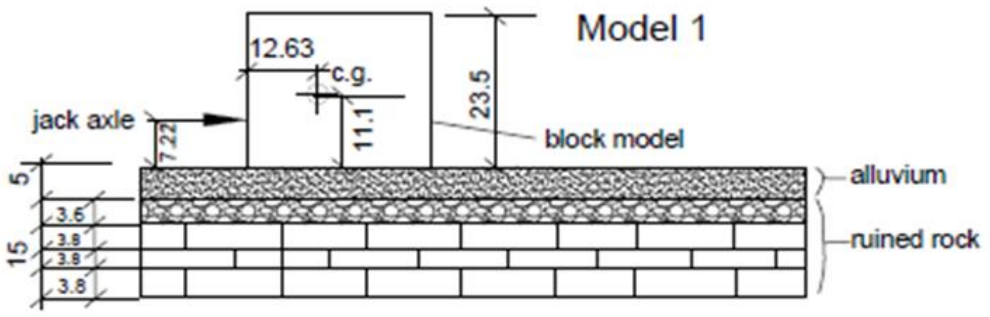

б)

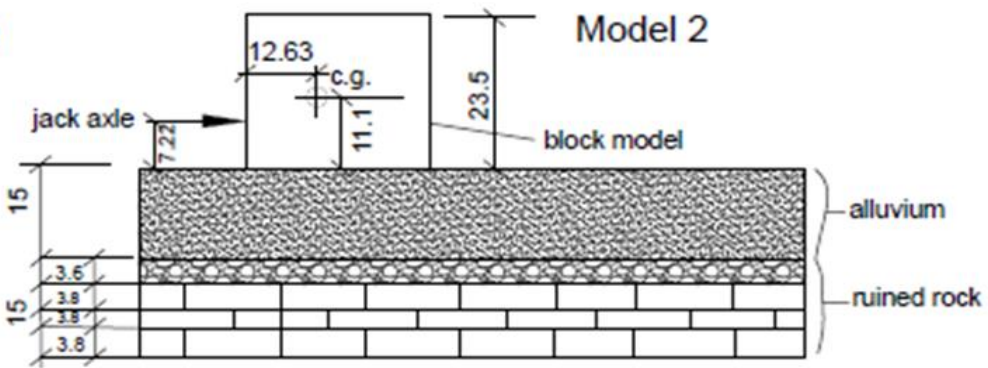

B)

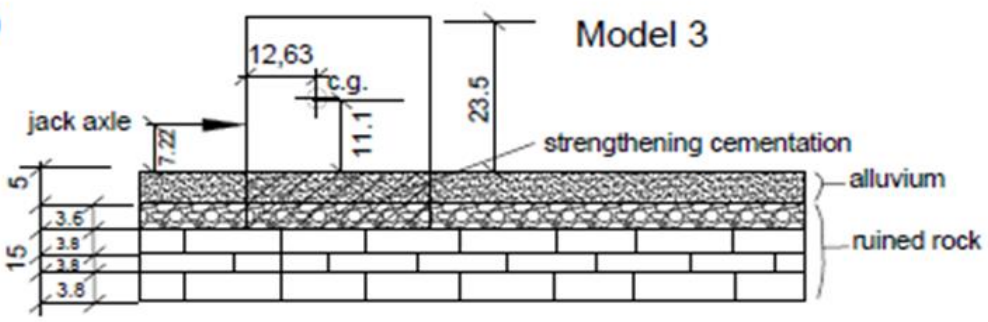

г)

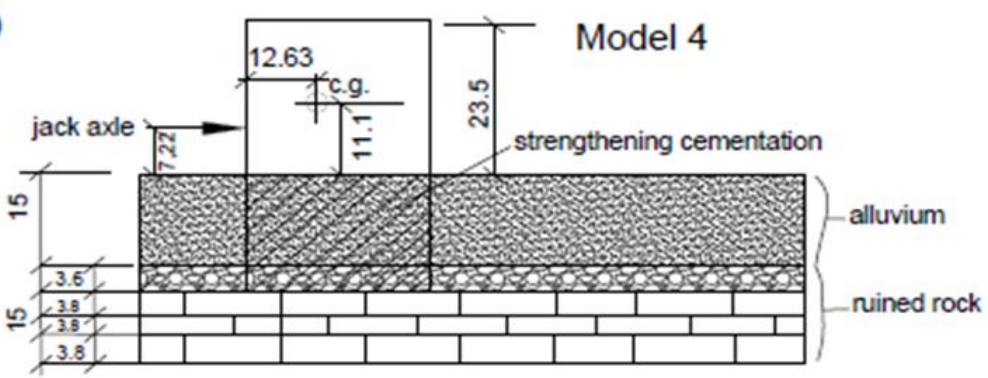

Top view of the model

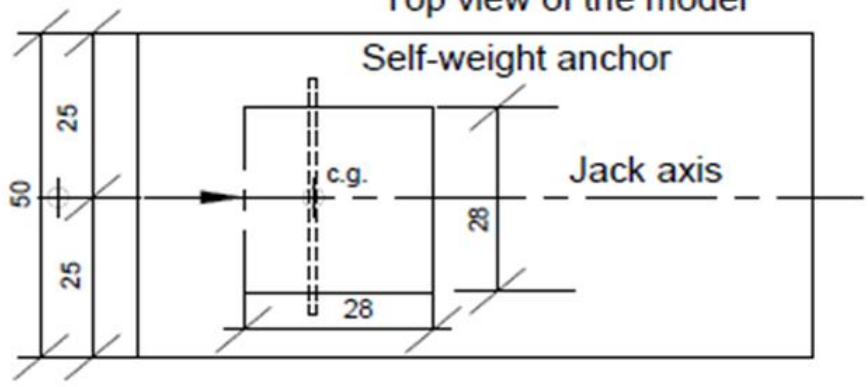

Fig. 3. Model test schemes 
Model No. 4 - the strengthening of the base of model No. 2 is simulated. Reinforcing cementation is performed at the full thickness of the alluvium and the upper tier of destroyed rock with a total depth of $18.6 \mathrm{~m}$ (18.6 cm on the model) (Figure $3 \mathrm{~d}$ ).

The initial characteristics are as follows:

for the reinforced part of the base by the area of the block foot to a depth of $18.6 \mathrm{~m}$ like model No. 3:

$\mathrm{c}=0.2 ; \varphi=36^{\circ}, \operatorname{tg} \varphi=0.73$.

For the rest of the alluvial base:

$\mathrm{c}=0, \varphi=39^{\circ}, \operatorname{tg} \varphi=0.8, \mathrm{E}=70$ Мпа.

For the bottom three layers of the underlying rock:

$\mathrm{c}=0.02 \div 0,2, \varphi=31^{\circ} \div 37^{\circ} ; \operatorname{tg} \varphi=0.6 \div 0.75, \mathrm{E}=1500$ Мпа.

The alluvial base was modeled with dry sand $\left(w_{a v} .=0,11\right)$ of the Lyubertsky quarry $\left(\mathrm{d}_{50}=0.22 \mathrm{~mm}\right)$. The sand was compacted into the base.

The physical and mechanical characteristics of the materials used for the model are given in Table 2.

The selected compositions for different horizons of the models' foundations allow, as can be seen from Table 2 to model rather well the ratio of the strength and shear characteristics of the "block-base" complex while maintaining the $E /{ }_{R}$ ratios for concrete of nature and the model, as well as the ratio of the normative characteristics of the block and bases of nature and model.

\subsection{Test bench and model loading systems}

Models of the floating block with their bases were tested in a stand (Figure 4), which is a rigid welded structure with internal dimensions: length $-320 \mathrm{~cm}$, width $-50 \mathrm{~cm}$; height $185 \mathrm{~cm}$. The dimensions of the stand allow placing two models in it at the same time. The load-bearing floor (2) is raised from the bottom of the standby $80 \mathrm{~cm}$. The bases of the models (3) are laid on it, and the block models (4) are installed. Through the holes in the load-bearing floor, the rods of its own weight (6) are passed, laid down in the model when it is cast in the center of gravity of the block, and the lower ones - to the loading beam of its own weight (7), with the help of two hydraulic jacks (8), located symmetrically relative to the longitudinal axis block, the model is loaded with its own weight.

The model is loaded with its own weight using a press (9), the pressure in the gravity system is controlled by a pressure gauge (10). A shear force is applied to the block model using a horizontally mounted hydrostatic load jack (11) and a die (12). The model is loaded with a hydrostatic load using a press (15), the pressure in the hydrostatic load system is controlled by a pressure gauge (16). 


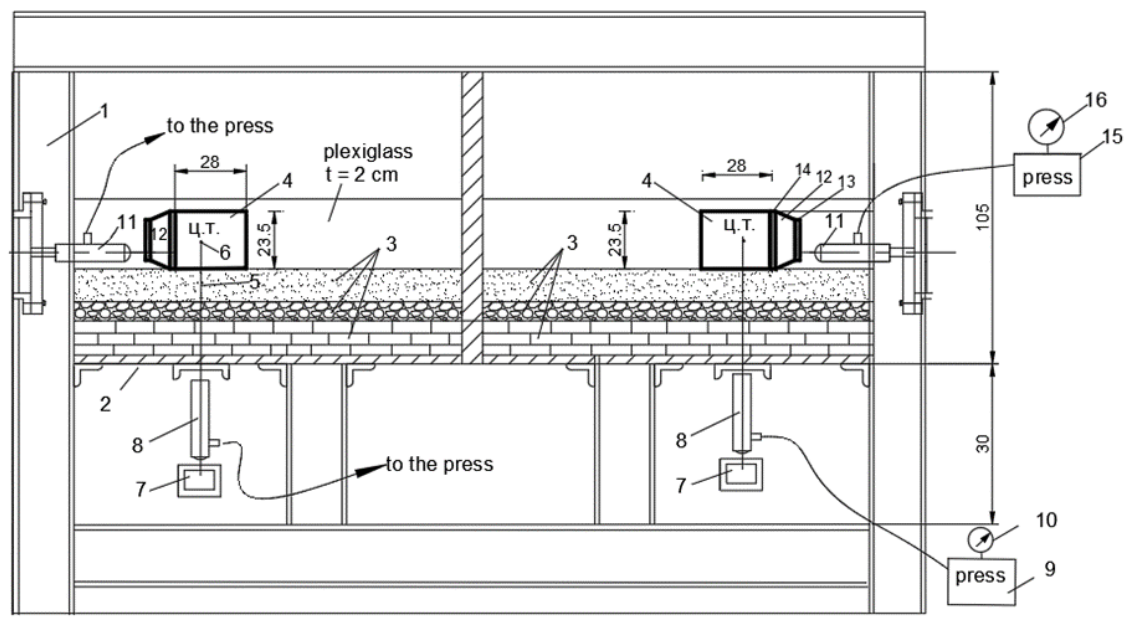

Fig. 4. Layout of models in the test bench

Table 2. Physical and mechanical characteristics of the compositions (for the selection of model materials)

\begin{tabular}{|c|c|c|c|c|c|c|}
\hline \multirow{2}{*}{ Composition index } & \multicolumn{5}{|c|}{ Components of the composition by weight } & $\begin{array}{c}\text { Volumetric } \\
\text { weight } \gamma, \mathrm{g} / \mathrm{cm}^{3}\end{array}$ \\
\cline { 2 - 7 } & $\mathrm{G}$ & $\mathrm{S}$ & $\mathrm{R}$ & $\mathrm{C}$ & $\mathrm{W}$ & \\
\hline 1 & 2 & 3 & 4 & 5 & 6 & 7 \\
\hline $\mathrm{A}-13$ & 1 & & 0.9 & & 1.33 & 0.77 \\
\hline $\mathrm{AE}-7$ & 1 & & 0.9 & & 1.4 & 0.93 \\
\hline $\mathrm{AE}-11$ & 1 & & 1.1 & & 1.5 & 0.68 \\
\hline $\mathrm{AE}-10$ & 1 & & 1.2 & & 1.5 & 0.70 \\
\hline $\mathrm{AB}-16$ & 1 & & 1.3 & & 1.33 & 0.75 \\
\hline $\mathrm{AE}-8$ & 1 & & 1.3 & & 1.7 & 0.65 \\
\hline $\mathrm{AE}-1$ & 1 & & 1.5 & & 1.75 & 0.17 \\
\hline $\mathrm{AE}-2$ & 1 & & 1.7 & & 1.9 & 0.65 \\
\hline $\mathrm{AE}-3$ & 1 & & 1.9 & & 2.05 & 0.64 \\
\hline $\mathrm{AD}-17$ & 1 & & 3 & & 2.5 & 0.66 \\
\hline $\mathrm{X}-13$ & 1 & & 1.45 & & 2.75 & 0.745 \\
\hline $\mathrm{X}-12$ & 1 & & 1.375 & & 2.75 & 0.688 \\
\hline $\mathrm{AB}-19$ & 1 & & & 1.25 & 2.5 & 0.72 \\
\hline $\mathrm{AE}-12$ & 1 & & & 1.375 & 2.75 & 0.688 \\
\hline $\mathrm{AE}-13$ & 1 & & & 1.45 & 2.75 & 0.745 \\
\hline $\mathrm{X}-10$ & 1 & 2 & & & 1 & 1.48 \\
\hline
\end{tabular}


Continued table 2

\begin{tabular}{|c|c|c|c|c|c|c|c|c|}
\hline 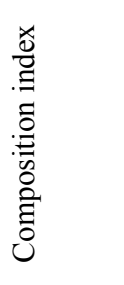 & 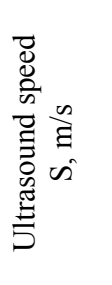 & 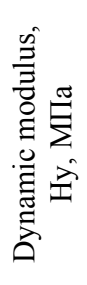 & 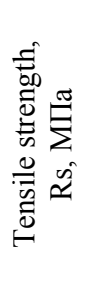 & 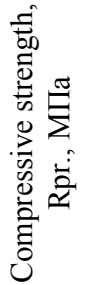 & 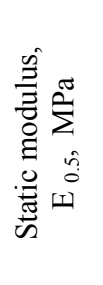 & 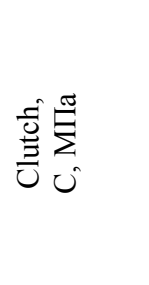 & 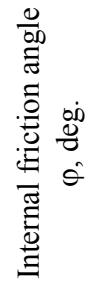 & $\begin{array}{l}\theta \\
00\end{array}$ \\
\hline 1 & 8 & 9 & 10 & 11 & 12 & 13 & 14 & 15 \\
\hline АБ - 13 & 1108.8 & 872 & 0.23 & 0.72 & 634 & $0.008 / 0.08$ & 27 & $\begin{array}{l}0.5096 / \\
0.5095\end{array}$ \\
\hline $\mathrm{AE}-7$ & 1437.1 & $\begin{array}{c}1773 . \\
4\end{array}$ & - & 1.53 & - & - & - & - \\
\hline $\mathrm{AE}-11$ & 910.2 & 525.3 & - & 0.385 & 338 & - & - & - \\
\hline $\mathrm{AE}-10$ & 867.4 & 488.1 & - & 0.40 & 305 & 0.11 & 33 & 0.6494 \\
\hline АБ - 16 & 877.0 & 536.0 & 0.15 & 0.42 & 400 & $\begin{array}{c}0.018 / 0.16 \\
8 \\
\end{array}$ & $\begin{array}{c}24 / 2 \\
2 \\
\end{array}$ & $\begin{array}{l}0.445 / \\
0.405 \\
\end{array}$ \\
\hline $\mathrm{AE}-8$ & 752.4 & $\begin{array}{c}341.9 \\
6 \\
\end{array}$ & - & 0.23 & 196.2 & - & - & - \\
\hline $\mathrm{AE}-1$ & 704.9 & 307.4 & - & 0.26 & 130.0 & 0.088 & 16.5 & 0.296 \\
\hline $\mathrm{AE}-2$ & 650.2 & 255.9 & - & 0.19 & 96.0 & 0.07 & 17.5 & 0.3153 \\
\hline $\mathrm{AE}-3$ & 624.0 & 230.1 & - & 0.22 & - & 0.067 & 16 & 0.2867 \\
\hline АБ -17 & 471.4 & 1371 & 0.317 & 0.09 & 698 & $0.025 / 0.03$ & $\approx 16$ & $\begin{array}{l}0.2867 / \\
0.2679 \\
\end{array}$ \\
\hline$X-13$ & 1279.1 & $\begin{array}{c}1129 . \\
4\end{array}$ & - & 0.65 & 657.6 & - & - & - \\
\hline $\mathrm{X}-12$ & 1256 & $\begin{array}{c}1006 . \\
5\end{array}$ & - & 0.569 & 490.1 & - & - & - \\
\hline АБ - 19 & 1139 & 862.3 & 0.13 & 0.54 & 526 & $0.006 / 0.05$ & $\begin{array}{c}38.5 \\
/ 35 . \\
6\end{array}$ & $\begin{array}{l}0.795 / \\
0.717\end{array}$ \\
\hline $\mathrm{AE}-12$ & 1256 & $\begin{array}{c}1006 . \\
5\end{array}$ & - & 0.569 & 490.1 & - & - & - \\
\hline $\mathrm{AE}-13$ & 1279.1 & $\begin{array}{c}1129 . \\
4\end{array}$ & - & 0.65 & 657.6 & - & - & - \\
\hline$X-10$ & 2175 & 6490 & 0.8 & 3.95 & 2980 & - & - & - \\
\hline
\end{tabular}

\subsection{Measuring equipment}

When carrying out experiments on the models, displacements were measured using dial indicators. The indicators were installed at the points shown in Figure 5. As can be seen from Figure 5, according to the readings of the indicators, in addition to the absolute values of the displacement values, it is possible to estimate the angles of rotation of the model in different planes and control the symmetry of the model.

\subsection{Scheme of the experiment}

All models were tested with bringing to failure in order to determine the coefficient of shear stability: 


$$
K=\mathrm{P}_{\text {destr.m. }} / \mathrm{P}_{\text {calc.m. }}
$$

Were: $\mathrm{P}_{\text {destr.m. }}$ - load at which destruction or loss of stability of the model occurs; $\mathrm{P}_{\text {calc.m. }}$ - (calculated) - design load on the model; $\mathrm{P}_{\text {calc.m. }}$. is recorded on the hydrostatic pressure gauge at the moments of destruction, that is, the impossibility of further increasing the load. Prior to the experiment, the model was preloaded by $0.2 P_{\text {calc. }}$ at $0.2 G_{\text {calc. In }}$ order to compress it, eliminate possible backlash in loading systems.

The model was tested at a constant value of its own weight $G_{\text {calc. }}$. It was taken into account that we have the initial load in the form of the own weight of the block and the loading beam, equal to $41 \mathrm{~kg}$, which is $0.11 G_{\text {calc }}$. Further, increase in the load was carried out in steps of $0.1 G_{\text {calc. }}$; the last stage is $0.09 G_{\text {calc. }}$.

The hydrostatic load increased up to destruction in steps of $0.1 P_{\text {calc. }}$.

At each stage of the load, both from its own weight and from hydrostatics, the displacements were measured: the first - immediately after loading, the second - after the time delay required to stabilize the deformations.

\section{Results and Discussion}

Indicator diagrams obtained in the process of testing models with bringing to destruction according to the indications of the displacement indicators installed on them reflect the movements of the floating block in kind $(\mathrm{mm})$ in the horizontal and vertical directions. The recalculation from model to nature was carried out, taking into account the linear scale $\propto_{l}$. The obtained displacement values show the joint displacements of the block with the base. As an example, we give indicator diagrams of horizontal displacements of model No. 1 (close to model No. 2) and model No. 4 (close to model No. 3) (Figures 5 and 6).

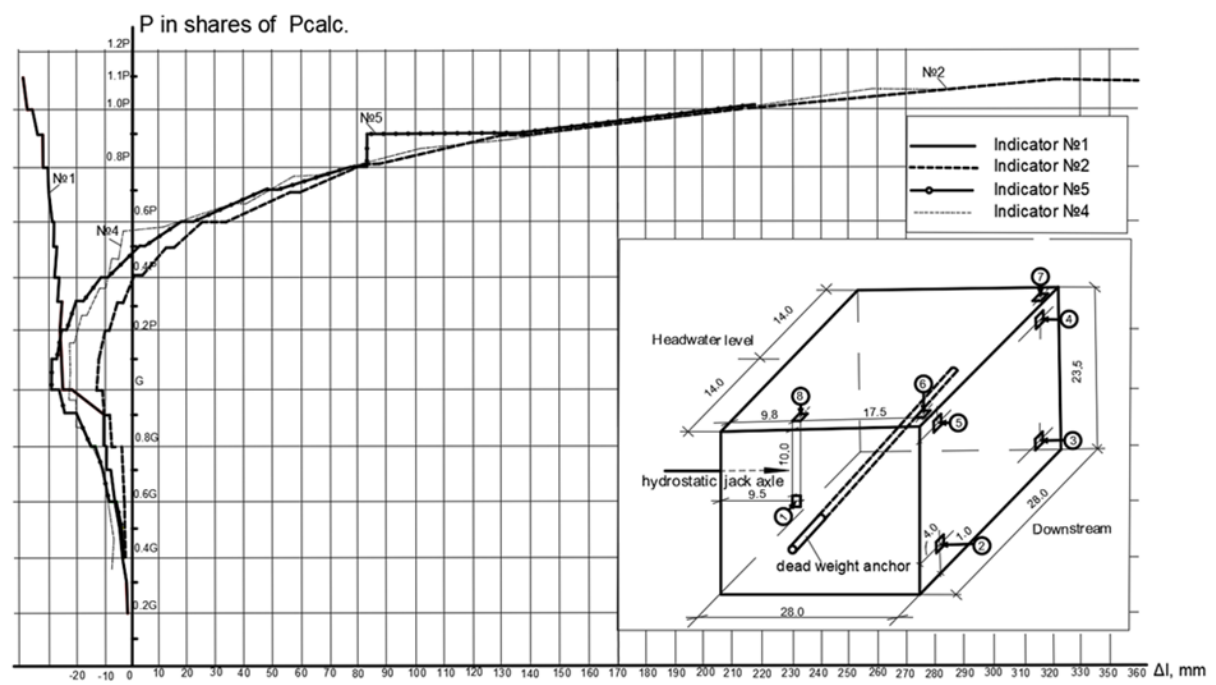

Fig. 5. Indicator diagrams of horizontal displacements of model No. 1 (No. 1 - side indicator with $10 \mathrm{~mm}$ travel; $2 \div 5$ - horizontal indicators with $25 \mathrm{~mm}$ travel; $6 \div 8$ - vertical indicators with $10 \mathrm{~mm}$ travel)

When loading all models both on an unreinforced and on a reinforced base only by their own weight, the growth of displacements, both vertical and horizontal, is linear. For 
example, in models No.1 and No.2, they are small and practically absent in models No.3 and No.4.

Upon reaching the calculated value of its own weight and subsequent loading of the models with hydrostatic load, the models on unreinforced alluvium show nonlinearity from the moment the hydrostatic load increases and occurs during the entire loading process.

For models on a reinforced base, sections of the diagrams can be distinguished that are close to linear at $(0.4 \div 0.5) P_{\text {calc. }}$. With a further increase in hydrostatic pressure, the indicator diagrams also become nonlinear.

Upon reaching $P_{\text {calc. }}$, the magnitude of horizontal displacements on an unreinforced base is $3 \div 5$ times higher than on a fortified one. For example, on models No. 1 and No. 2, they reached $81 \mathrm{~mm}$ and $66 \mathrm{~mm}$, respectively, and on models No. 3 and No. 4, respectively, $17 \mathrm{~mm}$ and $25 \mathrm{~mm}$ (Figure 7).

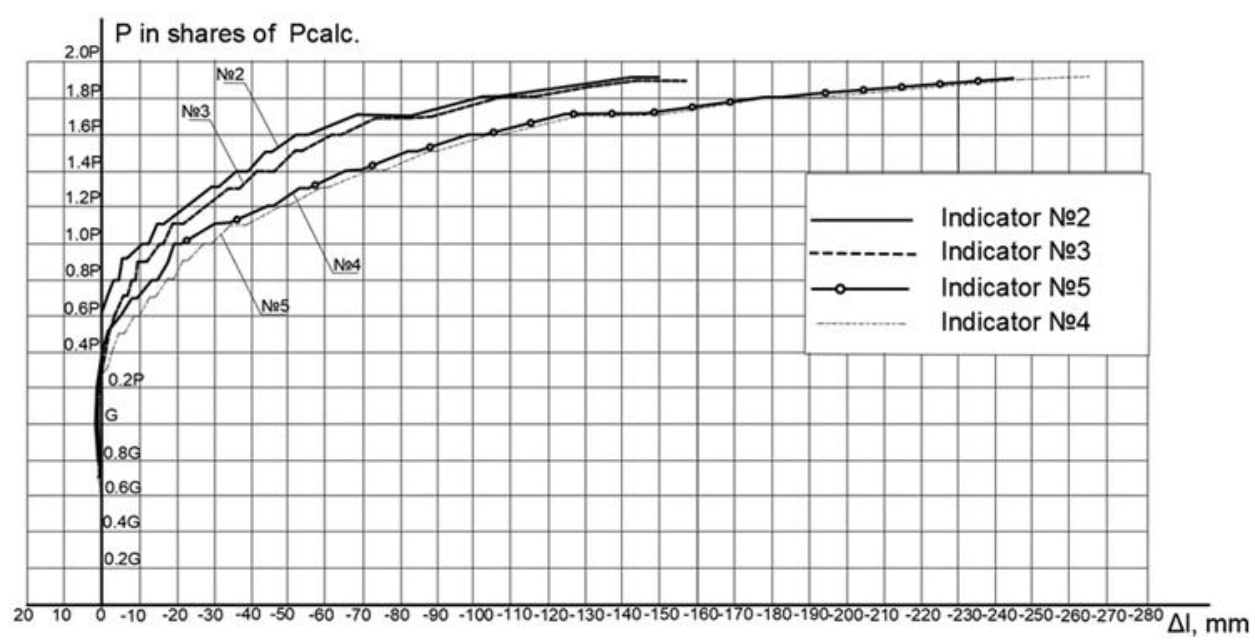

Fig. 6. Indicator diagrams of horizontal displacements of model No.4 (No. 1) are lateral indicators with a stroke of $10 \mathrm{~mm} ; 2 \div 5$ are horizontal indicators with a stroke of $25 \mathrm{~mm} ; 6 \div 8$ are vertical indicators with a stroke of $10 \mathrm{~mm}$ - see Fig. 5).

\subsection{Pictures of destruction}

Analysis of the fracture patterns allows us to note that the loss of the bearing capacity of all models was due to a shear that took place with an increase in the hydrostatic load.

Model No. 1 (thickness of the alluvium layer $5 \mathrm{~m}$ ) collapsed at $1.1 P_{\text {calc. }}$. a shift was noted along the unreinforced alluvial base, accompanied by sedimentation of the lower part of the block and soil uplift in the downstream. During disassembly of the model and removal of the block, the surface shear track had the character of a flat smoothed area with a slope towards the downstream. The depth of the track at the lower edge of the model was about $1 \mathrm{~cm}$.

During the unloading of sand and expanded clay after the experiment, deformations of the model of the underlying rock of zone A2 in the form of a rectangular track $0.5 \div 1 \mathrm{~mm}$ deep were also noted.

Model No. 2 (thickness of the alluvium layer $15 \mathrm{~m}$ ) collapsed at $1.7 P_{\text {calc. }}$ The shear pattern is similar to model No. 1. A similar footprint is noted in the sandy base. However, the significant thickness of the alluvium layer compared with model No. 1 prevented the destruction of the underlying rocks $\mathrm{A} 1$ and $\mathrm{A} 2$. No deformations or destruction were recorded in these parts of the $\mathrm{A} 1$ and $\mathrm{A} 2$ rocks. 
Model No. 3 (reinforced alluvium $5 \mathrm{~m}$ thick). Loss of bearing capacity was due to shear at $2.2 P_{\text {calc. }}$ During failure, a small uplift of soil in downstream was noted. The shift took place along the bottom of the fortified part of the alluvial base model, just above the contact plane "fortified soil - rock of zone A2". At the same time, the model of the rock base did not collapse (Figure 7).

Model No 4 (reinforced alluvium $15 \mathrm{~m}$ thick). The model collapsed at $1.9 P_{\text {calc. }}$ The destruction occurred similarly to model No. 3, which was also found during disassembly and inspection of the model (Figure 7).

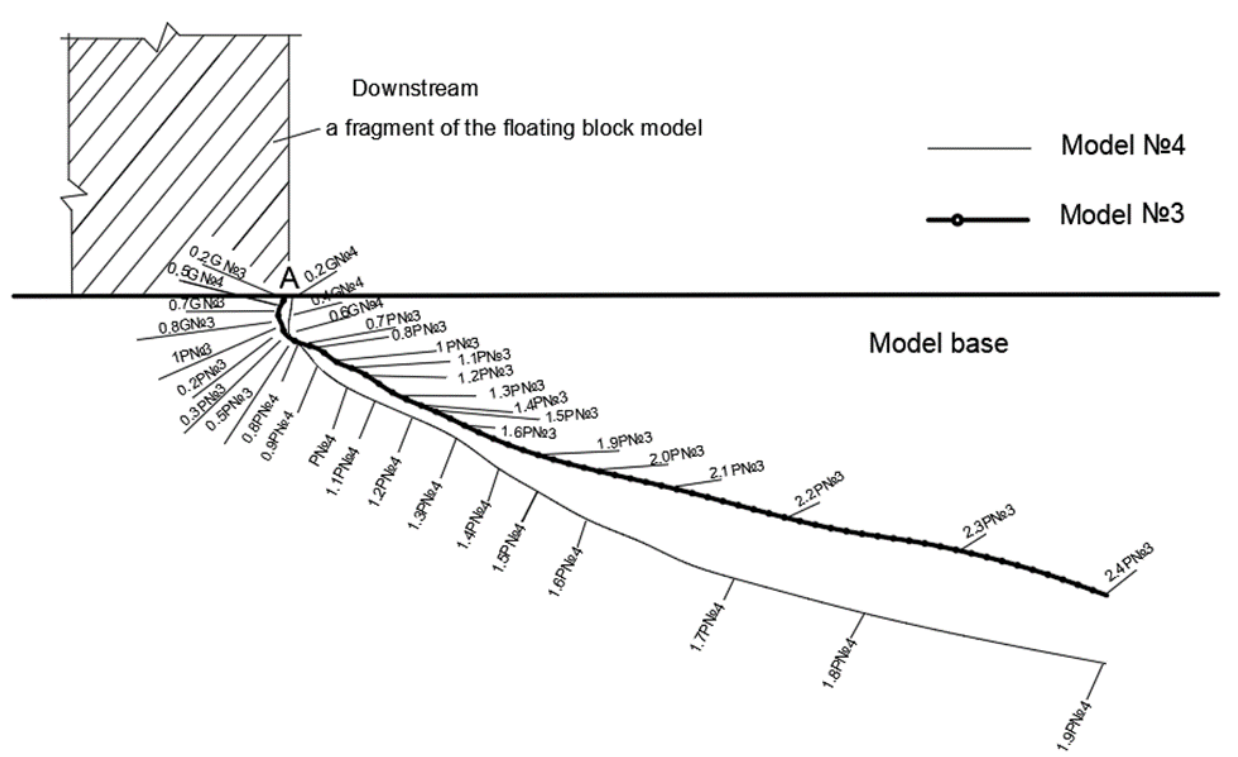

Fig. 7. Trajectories of displacements referred to point A of the bottom face of the floating block

\subsection{Safety factor}

When testing models of a floating Hydroelectric power station block on unreinforced alluvial foundations of various capacities, and after reinforcing cementation, shear stability factors were obtained.

The following safety factors were obtained:

for model No. $1-K_{\text {saf. }}=1.1$;

for model No. 2 - $\mathrm{K}_{\text {saf. }}=1.7$;

for model No. $3-\mathrm{K}_{\text {saf. }}=2.2$;

for model No. $4-K_{\text {saf. }}=1.9$.

The value of the standard generalized safety factor $K=\frac{\gamma_{n} \gamma_{l c}}{\gamma_{c d}}$, where

$\gamma_{n}$ is reliability coefficient for the purpose of structures; for class I structures $\gamma_{n}=1.25$;

$\gamma_{l c}$ is load combination ratio; for the main combination of loads $\gamma_{l c}=1$; for the period of construction and renovation $\gamma_{l c}=0.95$;

$\gamma_{c d}$ is coefficient of working conditions when calculating the stability of dams on nonrocky foundations, $\gamma_{c d}=1$.

Thus, for the period of operation with the main combination of loads $K=\frac{1.25 \times 1.0}{1}=$ 1.25 , and for the repair period (the case we are considering is the repair of the suction pipe) $K=\frac{1.25 \times 0.95}{1}=1.18$. 
The obtained values of the shear safety factors allow us to note the following: an increase in the shear characteristics during cementation of an alluvial base with a thickness of $15 \mathrm{~m}$ leads to an increase in the safety factor to 1.7 (model No. 3) and to 1.9 (model No. 4), that is, by more than $15 \%$.

To a greater extent, cementation affected the strengthening of the base with a thickness of $5 \mathrm{~m}$ : in this case, the value of the coefficient increases very significantly from 1.1 to 2.2.

\section{Conclusions}

1. We have tested four models of a floating hydroelectric power plant block on alluvial foundations of various capacities without their strengthening and after reinforcing cementation. The values of the generalized shear safety factors are obtained: model No. 1 1.1; Model No. 2 - 1.7; Model No. 3 - 2.2; Model No. 4 - 1.9.

2. Comparing the safety factors obtained in the experiments with the normative ones makes it possible to consider it impossible to install a floating block on an unreinforced alluvial foundation with an alluvium layer thickness of $5 \mathrm{~m}$. Carrying out reinforcing cementation, in this case, ensures the shear stability of the structure. With an alluvium layer thickness of $15 \mathrm{~m}$, the shear stability of the floating block is ensured even in the absence of reinforcing cementation.

3. As a result of testing models No. 3 and No. 4 on hardened alluvium, a new limiting state diagram was obtained - the shift of the model of the floating block together with a part of the fortified base along the buried underlying rock.

4. The conducted studies have shown that despite the clear advantage of using floating blocks, which allow their installation directly on the base without setting up an expensive excavation under the bottom of the structure, it can lead to adverse consequences during the construction and operation period with an insufficient assessment of the strength characteristics of the underlying soil. In this case, any modern bottom structure of the floating block will not improve the situation.

5. The presented materials are of great practical interest. It can be used in the future to develop simplified calculation methods and substantiate the reliability of various design options.

\section{References}

1. Jacobson, Mark Z., Delucchi, Mark A. Providing all global energy with wind, water, and solar power, Part I: Technologies, energy resources, quantities and areas of infrastructure, and materials. J. Energy Policy. 39(3) pp.1154-1169. (2011)

2. Rubin O D, Novikov S P. Computational studies of floating reinforced concrete blocks for the Northern Tidal Power Plant. J. Prirodoobustroistvo 3 pp. 60-63. (2012)

3. Bakshtanin A.M., Krylov A.P., Matveeva T.I., Beglyarova E.S. Technical realization of the project of severnaya tidal power plant in the Barents sea. J. Prirodoobustroistvo 5. pp. 59-67. (2020)

4. Aydar Nasrulin, Dilbar Ergasheva, Bekmamat Khamdamov and Fatima Shadibekova. Environmental monitoring in construction for hydro-technical structures and land reclamation facilities of Uzbekistan. IOP Conf. Series: Materials Science and Engineering. 1030 pp. 012102. (2021)

5. Ren Xuhua, Shu Jiaqing, Ben Nenghui, Ren Hongyun, Stability analysis of concrete gravity dam on complicated foundation with multiple slide planes. J. Water Science and Engineering. 1(3) pp. 65-72. (2008)

6. Krounis A, Johansson F, Larsson S. Effects of spatial variation in cohesion over the 
concrete-rock interface on dam sliding stability. J. of Rock Mechanics and Geotechnical Engineering. 7. pp. 659-667. (2015)

7. Xiaoling Wang, Hongling Yu, Peng Lv, Cheng Wang, Jun Zhang, Jia Yu, Seepage safety assessment of concrete gravity dam based on matter-element extension model and FDA. J. Energies 12(3). pp. 21 (2015)

8. Ali, Md. Hazrat, Alam, M. R., Haque, M. N., Alam, M. J. Comparison of the structural stability of gravity concrete dams using USACE and USBR standards. J. Natural Resources. 3(1) pp. 18-28. (2013)

9. Hellgren, Rikard, Malm, Richard, Ansell, Anders. Progressive failure analysis of a concrete dam anchored with passive rock bolts. J. Infrastructures. 5(3). pp. 5030028 (1-14). (2020)

10. Bista, Dipen, Sas, Gabriel, Johansson, Fredrik, Lia, Leif. Influence of location of large-scale asperity on shear strength of concrete-rock interface under eccentric load. Journal of Rock Mechanics and Geotechnical Engineering. 12(3). pp. 449-460. (2020)

11. Zimnyukov V.A. and Zborovskaya M.I. Role of temperature factor in the work of a cellular reinforced concrete ice-resistant platform. IOP Conference Series: Materials Science and Engineering, 911.pp. 012010 (1-9). (2020) 